\title{
Guy de Maupassant, Nouvelles animalières
}

\section{Maria Emanuela Raffi}

\section{(2) OpenEdition}

\section{Journals}

\section{Edizione digitale}

URL: http://journals.openedition.org/studifrancesi/5407

DOI: 10.4000/studifrancesi.5407

ISSN: 2427-5856

\section{Editore}

Rosenberg \& Sellier

\section{Edizione cartacea}

Data di pubblicazione: 1 dicembre 2016

Paginazione: 556

ISSN: 0039-2944

\section{Notizia bibliografica digitale}

Maria Emanuela Raffi, «Guy de Maupassant, Nouvelles animalières », Studi Francesi [Online], 180 (LX

III) | 2016, online dal 01 janvier 2017, consultato il 18 septembre 2020. URL : http://

journals.openedition.org/studifrancesi/5407 ; DOI : https://doi.org/10.4000/studifrancesi.5407

\section{Questo documento è stato generato automaticamente il 18 settembre 2020.}

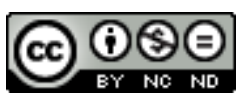

Studi Francesi è distribuita con Licenza Creative Commons Attribuzione - Non commerciale - Non opere derivate 4.0 Internazionale. 


\title{
Guy de Maupassant, Nouvelles animalières
}

\author{
Maria Emanuela Raffi
}

\section{NOTIZIA}

GUY DE MAUPASSANT, Nouvelles animalières, textes choisis, dossier par François Kerlouégan, lecture d'image par Pierre-Olivier Douphis, Paris, Gallimard, 2016, pp. 5-100 + 103-187.

1 Undici novelle di Maupassant tratte da raccolte diverse, ma tutte con animali protagonisti - Toine, Souvenir, Misti, La Roche aux guillemots, Le Loup, Une vendetta, Amour, Pierrot, Le Noyé, Mademoiselle Cocotte, Coco - compongono la scelta di Kergouégan per questo volumetto di «Folioplus classiques», corredato da un dossier didattico dello stesso autore e da un saggio di Pierre-Olivier Douphis, Du tableau aux nouvelles, su un quadro del pittore inglese Edwin Henry Landseer, autore di numerose tele con scene di animali: A Jack in Office. 